\title{
Impacto de la consulta de enfermería sobre los parámetros de salud del paciente en hemodiálisis
}

\author{
Maㅡㄹ Elena Viudes Flores, Montserrat García Zamora, Ma José Gordo García, Tamara López Ramos
}

\section{Corporació Sanitària Parc Taulí. Sabadell. Barcelona}

\section{Introducción:}

La consulta de enfermería (CE) es una herramienta imprescindible en el tratamiento sustitutivo renal, ya que proporciona al paciente y a su familia los conocimientos y habilidades necesarios para el autocuidado (tratamiento dietético, tratamiento farmacológico, cuidado del acceso vascular, complicaciones, etc.). Sin embargo, en la actualidad, existen pocas referencias bibliográficas y/o estudios relacionados con la misma, por lo que se carece de referentes para su sistematización, metodología, etc. y no se dispone de análisis de resultados que avalen su eficacia.

\section{Objetivo:}

Evaluar el impacto de la CE sobre el peso acumulado y parámetros analíticos del paciente en hemodiálisis.

\section{Material y métodos:}

Estudio descriptivo, longitudinal y retrospectivo, realizado a 121 pacientes en programa de hemodiálisis en nuestro hospital que recibían tratamiento en 0ctubre del 2011. Se analizó:

- El peso acumulado inter-diálisis, realizando el promedio de las 14 sesiones previas a la CE y de las 14 posteriores.

- La variación en las determinaciones en sangre de K, P y Ca de la analítica previa a la realización de la $C E$, en relación a las tres analíticas posteriores llevadas a cabo de manera consecutiva y separadas cada una de ellas por un intervalo aproximado de
2 meses, registrando además si se habían producido modificaciones en el tratamiento farmacológico.

- Análisis estadístico mediante SPSS/21 y prueba t de Student para datos apareados.

\section{Resultados:}

En relación a los pesos, en el grupo de pacientes que antes de la CE acumulaban más de $2 \mathrm{~kg}$, la intervención consigue disminuir el promedio en un $51.6 \%$ de los casos (más de $0.5 \mathrm{~kg}$ en un $16.6 \%$ y entre $0.1-0.5 \mathrm{~kg}$ en un $35 \%$ ). Analizando la t de Student apareada se observó una disminución de $0.2 \mathrm{~kg}$ de promedio $(\mathrm{P}=0.001$ ). Los pacientes que acumulaban menos de $2 \mathrm{~kg}$ antes de la CE mantienen pesos similares en un $85.1 \%$.

En relación a los resultados analíticos, se observa que, sin haber introducido cambios en el tratamiento farmacológico:

- Mejoran significativamente en las determinaciones:

- Potasio: $1^{a}$ analítica: 19,8\%; $2^{\mathrm{a}}$ analítica: 20,6\%; $3^{\mathrm{a}}$ analítica: 19\%; en las 3 analíticas: 9,9\%.

- Fósforo: $1^{\mathrm{a}}$ analítica: 15,2\%; $2^{\mathrm{a}}$ analítica: $22,5 \% ; 3^{\mathrm{a}}$ analítica: $17,5 \%$; en las 3 analíticas: $5,9 \%$.

- Calcio: $1^{\mathrm{a}}$ analítica: 5\%; $2^{\mathrm{a}}$ analítica: $10 \% ; 3^{\mathrm{a}}$ analítica: 4,1\%; en las 3 analíticas:2,5\%.

- Se mantienen dentro de los límites de la normalidad: - Potasio: $1^{\mathrm{a}}$ analítica: $33 \% ; 2^{\mathrm{a}}$ analítica: $31,1 \%$; $3^{a}$ analítica: $33,8 \%$; en las 3 analíticas: $21,5 \%$

- Fósforo: $1^{\mathrm{a}}$ analítica: $28,8 \% ; 2^{\mathrm{a}}$ analítica: $24,1 \%$; $3^{\mathrm{a}}$ analítica: $26,6 \%$; en las 3 analíticas: $11 \%$. 
- Calcio: $1^{\mathrm{a}}$ analítica: 50,4\%; $2^{\mathrm{a}}$ analítica: 57,5\%; $3^{a}$ analítica: 55,8\%; en las 3 analíticas: $30,2 \%$

Los resultados de la t de Student apareada oscilan entre $\mathrm{P}=0.001$ y $\mathrm{P}=0.017$ dependiendo de la variable analizada.

\section{Conclusiones:}

La CE en Hemodiálisis mejora los parámetros de salud evaluados en este estudio. Se evidencia la dificultad de mantener los resultados durante los 6 meses que dura el estudio, por lo que parece necesario, a medio plazo, reforzar las habilidades y conocimientos adquiridos por el paciente, para evitar la reaparición de conductas no deseadas.

\section{Referencias Bibliográficas}

1. Alimentación en Pacientes Renales en Hemodiálisis. Disponible en: http://www.hacerdieta.com/ category/dieta-en-la-insuficiecia-renal-cronica/.

2. Alimentos saludables para hemodiálisis. American Kidney Fund. Disponible en: http://www.kidneyfund.org.

3. Carrascal Sonia E, Castell Prat M. ¿Qué puedo comer ahora que estoy en programa de Hemodiálisis? Servicio de Nefrología-Servicio de Endocrinología y Nutrición. Hospital General de Vic- Nefrología. Disponible en: http://www.alcer.es/mm/File/publicaciones/programa.pdf.

4. Contreras MD, Rivero MF, Jurado MJ, Crespo R. Perfil actual del paciente en hemodiálisis hospitalaria. Análisis de sus necesidades. Revista Seden. Ene- mar 2004;7(1):56- 61.

5. Fortuny M, Cruz Molina M: Educació per a la salut. Universitat de Barcelona, 1998.

6. García Margallo Solo de Zaldivar P. 11.440 Menús semanales para enfermos renales crónicos. Revisión y adaptación: Morgollón Cecilia. Depósito legal: SE-2802-2008. Edita: Junta de Andalucía. Conserjería de Salud.
7. Hernández Meca M $M^{a}$ Encarnación, Ochando García Antonio, Mora Canales Javier, Lorenzo Martínez Susana, López Revuelta Katia. Satisfacción del paciente en una unidad de hemodiálisis: Objetivo de calidad asistencial en enfermería. Rev Sociedad Española Enfermería Nefrológica 2005; 8(2):90/96.

8. Medicina XXI - Ciencia Medicina, Salud y Paciente. Nefro- Web de Nefrología y Urología. Disponible en: http://www.nefronet.com/.

9. Noriega Morán C. La alimentación en diálisis. Depósito legal: AS- 973-92.

10. Pascual $R$, Andreu L. El programa de educación sanitaria del paciente en hemodiálisis. Comunicación XV Congreso SEDEN 1998; 115- 126.

11. Recomendaciones dietéticas generales para Hemodiálisis. Federación Alcer Aragón. Disponible en: http://www.alcer.org/es/.

12. Reichert J. Consultas e ingresos hospitalarios de una población de un centro de Diálisis. Revista Nefrología 2007;27(1):53-61.

13. Rota Musoll Laura, Yuste Giménez Elios, Mañe Buixó Núria, García Jiménez Esther, Marcet Durán Montse, Marquina Parra Dolors, Ramírez Prat Núria. Diseño de una consulta de enfermería. Educación a los pacientes en hemodiálisis. Comunicación presentada al XXVII Congreso Nacional de la Sociedad Española de Nefrología 2002.

14. Russolillo Femenías G. Comer y Beber en Diálisis y trasplante renal. Depósito legal: V-4148-2002.

15. Russolillo Femenías G. Comer y Beber en la Enfermedad Renal Crónica Avanzada. SEN - SEDEN. Edita: Baxter.

16. Yuste $E$, Ramírez J, Marcet $M$, Jímenez MJ, López MJ, Padilla J, Ramírez N, Solano M. Una nueva metodología para la evaluación de la calidad asistencial. Libro de comunicaciones presentadas al XXI congreso de la Sociedad Española de Enfermería Nefrológica. [serie en internet] Salamanca 29Sept 2 Octubre 1996. 